\title{
Saying farewell and welcoming new leadership
}

\author{
Christopher J. Cramer
}

Published online: 4 September 2014

(C) Springer-Verlag Berlin Heidelberg 2014

It has been a privilege to serve, since the year 2000, as the 4th Editor-in-Chief for theoretical chemistry accounts (TCA). Founded in 1962, TCA remains the oldest journal devoted exclusively to publishing developments and applications of theoretical chemistry. As a legacy of the prior Editors-in-Chief as well-Hermann Hartmann, Klaus Ruedenberg, and Don Truhlar-TCA continues to serve the broader Chemistry community with distinction. Mindful of that legacy, I believe that it is time to turn the reins of editorship over to a new pair of scholars particularly well suited to maintain TCA's high standards while at the same time broadening its reach and the diversity of topics that it covers. I am delighted to announce that Carlo Adamo and Ilaria Ciofini have agreed to take on this responsibility, and I am confident that they will continue the journal's commitment to excellence in service to the theoretical chemistry community.

In my time as Editor-in-Chief, TCA launched a number of initiatives, including a switch to consecutive publishing, where all articles become published and can be cited immediately after the return of proofs. In recent years, we have also published a number of special collections, including a New Century issue (in Vol. 103, nos. 3-4, 2000, with perspectives on influential papers from the previous century) and a 50th anniversary issue (in Vol. 131, 2012, summarizing past accomplishments and offering thoughts about the future). Because of consecutive publishing, papers in such collections are not delayed by any need to await completion of the "slowest" contribution, and authors have responded quite favorably to this modus operandi. In addition, to accommodate authors who want more options with respect to Open Access publishing, TCA adopted and continues to adhere to a Green Open Access self-archiving model and a hybrid Gold Open Access publishing model.

Another hallmark of TCA has been its commitment to the publication of feature articles by established and emerging leaders in the theoretical/computational field. We have worked with authors to ensure that the feature article style is very flexible-for example with regard to page length-with the goal of providing an overview of a model or of an area but with the key difference from feature articles in many other journals is that such articles in TCA may be directed to an audience of theoretical chemists rather than to a broader audience that may be less knowledgeable about theoretical concerns.

I would be remiss in departing if I failed to express my gratitude to the many individuals whose contributions were seminal to the ongoing success of TCA during my own time as Editor. These include the publishing editors from Springer with whom I have worked, the production staff, my advisory and associate editors, members of the editorial board, and first and foremost, the authors and reviewers who have advanced our field through their scholarly contributions to TCA over the years. With the continued support of these many talented individuals, I am certain that TCA will maintain its preeminence under the leadership of Drs. Adamo and Ciofini, and I wish them all success moving forward.
C. J. Cramer $(\bowtie)$

Department of Chemistry, Supercomputing Institute, and Chemical Theory Center, 207 Pleasant St. SE,

Minneapolis, MN, USA

e-mail: cramer@umn.edu 